\title{
O EMPREGO DO CORPO DE FUZILEIROS NAVAIS \\ NAS OPERAÇÕES HUMANITÁRIAS
}

\author{
Raphael Correia Lopes \\ Batalhão Logístico do Corpo de Fuzileiros Navais / PUC-RJ \\ e-mail: raphamanaus@hotmail.com \\ Marcos dos Santos \\ Centro de Análises de Sistemas Navais - CASNAV \\ e-mail: marcosdossantos_coppe_ufrj@yahoo.com.br
}

\begin{abstract}
RESUMO
Este trabalho apresenta o emprego do Corpo de Fuzileiros Navais (CFN) da Marinha do Brasil dentro do escopo das operações humanitárias, quer seja no Brasil ou no exterior, em apoio as Nações Unidas ou a uma nação amiga que solicite este tipo de apoio. O objetivo é mostrar as características e peculiaridades das atividades de um Grupamento Operativo de Fuzileiros Navais em situações reais que necessitem um planejamento de logística humanitária, tais como o terremoto no Chile (2010) e os desabamentos em Nova Friburgo (2011).
\end{abstract}

Palavras-Chaves: Corpo de Fuzileiros Navais; Desastres, Operações Humanitárias; Logística Humanitária

\begin{abstract}
This work shows how to use of the Brazilian Navy Marine Corps within the scope of the humanitarian operations, either in Brazil or foreign country, in support of the United Nations or a friendly nation that requests this type of support. our goal is to show the characteristics and peculiarities of a Marine Corps Operational Group in real situations requiring humanitarian logistics planning, as in the earthquake in Chile (2010) or in landslides in Nova Friburgo (2011).
\end{abstract}

Keywords: Marine Corps, Disasters, Humanitarian Operations, Humanitarian Logistics 


\section{Introdução}

De acordo com a Estratégia Nacional de Defesa, para assegurar sua capacidade de projeção de poder, a Marinha do Brasil deve possuir meios de Fuzileiros Navais em permanente condição de pronto emprego e uma de suas tarefas é atuar em operações humanitárias em qualquer lugar do mundo. Com isso, o Corpo de Fuzileiros Navais consolida-se como a força de caráter expedicionário por excelência.

A Doutrina Básica da Marinha prevê o emprego do Poder Naval, quando necessário, de acordo com a legislação em vigor, em ações que lhe forem acometidas, em decorrência da participação da Marinha do Brasil no Sistema Nacional de Defesa Civil. Nesta mesma doutrina, operação humanitária é definida como operação realizada normalmente para reduzir os efeitos de desastres naturais ou acidentes provocados pelo homem que represente séria ameaça à vida ou resultem em extenso dano ou perda de propriedade, e para prestar assistência cívico-social.

Essencialmente para os humanitários, logística é o processo e os sistemas envolvidos em mobilizar pessoas, recursos, habilidades e conhecimento para ajudar pessoas vulneráveis afetadas por desastre (Thomas e Mizushima, 2005).

Baseado nas definições acima, verifica-se uma relação muito próxima entre a operação humanitária e a logística humanitária, fato este que será apresentado no artigo, paralelamente com a aplicação prática pelo Corpo de Fuzileiros Navais (CFN).

\section{Estrutura Operativa dos Fuzileiros Navais}

O emprego operativo de tropa de Fuzileiros Navais para o cumprimento de missão especifica normalmente dá-se na forma de Grupamento Operativo de Fuzileiros Navais (GptOpFuzNav), o qual está estruturado segundo o conceito organizacional de componentes, que agrupa os elementos constitutivos, de acordo com a natureza de suas atividades.

O conceito de GptOpFuzNav permite aliviar o seu Comandante da sobrecarga resultante da complexidade das atividades de manobra terrestre, de apoio logístico e daquelas relacionadas com o espaço aéreo de sua responsabilidade, além de facilitar a coordenação e o controle da Força.

Os GptOpFuzNav são constituídos, fundamentalmente, pelos seguintes componentes: Componente de Comando (CCmdo), Componente de Combate Terrestre (CCT), Componente de Apoio de Serviços ao Combate (CASC) e Componente de Combate Aéreo (CCA), conforme a figura 1 .

Figura 1 - Componentes do GptOpFuzNav

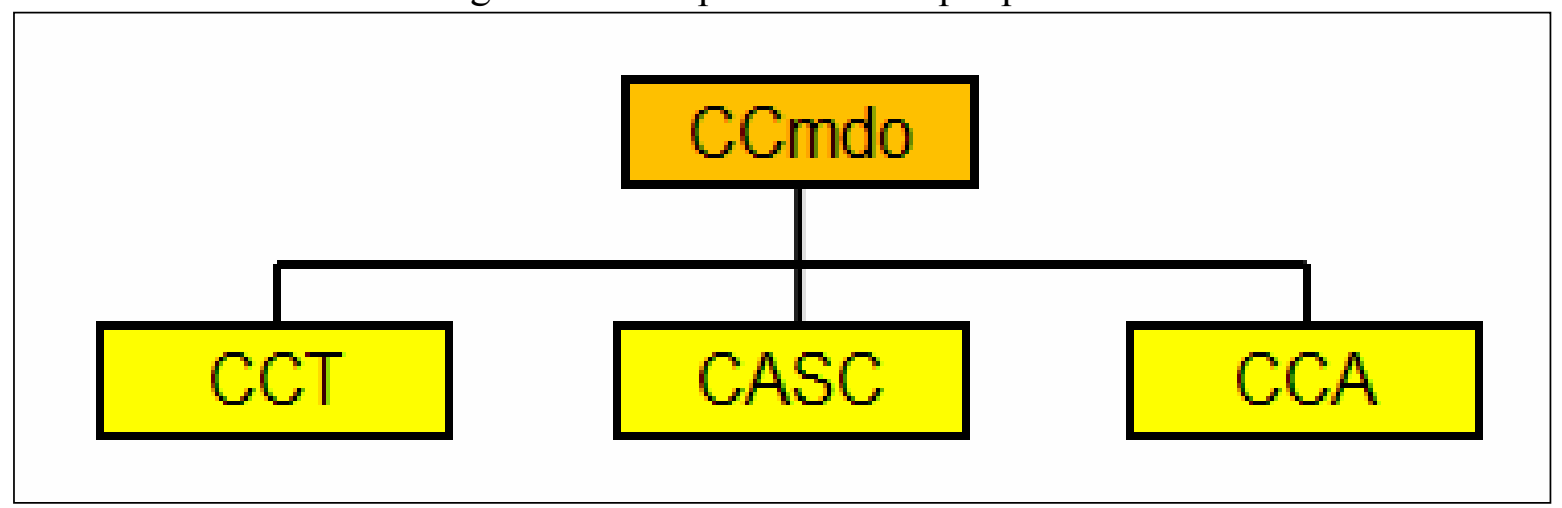

Fonte: (CGCFN 0-1, 2013) 
Duas principais características das Operações Humanitárias condicionam a organização e o emprego dos Grupamentos Operativos de Fuzileiros Navais. A primeira delas é que o ambiente onde são desenvolvidas as Operações Humanitárias é permeado pela presença e intensa atividade de agências de diversos organismos internacionais, de organizações não governamentais $(\mathrm{ONG})$ e de órgãos de defesa civil. A outra característica é a preponderância do esforço logístico sobre as demais atividades de combate.

O Componente de Comando (CCmdo) tem um papel importante de coordenação, tendo em vista a grande demanda entre as ações do GptOpFuzNav e as atividades desenvolvidas pelas agencias civis.

O Componente de Combate Terrestre (CCT) terá como tarefas as atividades relacionadas diretamente com a segurança de instalações e comboios, com o estabelecimento de postos de controle de trânsito, com ações de controle de distúrbios, além de constituir uma força de resposta rápida que garanta a segurança das ações do CASC.

O Componente de Apoio de Serviços ao Combate (CASC) exercerá o esforço principal do GptOpFuzNav. O foco das atividades logísticas estará voltado principalmente para o apoio externo, visando tanto a população vitimada como as diversas agências civis de ajuda humanitária. Este componente passa então a constituir a principal ferramenta que o comandante do GptOpFuzNav disporá para cumprir sua missão, os demais componentes, por sua vez, deverão canalizar seus esforços para facilitar e viabilizar as atividades logísticas.

O Componente de Combate Aéreo (CCA) realiza suas tarefas por meio do planejamento, coordenação e controle do emprego das aeronaves na Área de Operações. Destacam-se as tarefas de reconhecimento aéreo, visando identificar os locais para a prestação de ajuda humanitária, e de apoio logístico, objetivando prover transporte de tropa e material em proveito da operação.

\section{Operações Civis-Militares}

O maior obstáculo enfrentado por equipes de logística humanitária tem sido a enorme complexidade das condições de operação nas quais têm que trabalhar para oferecer ajuda aos afetados pelo desastre. As áreas são de difícil acesso, já que após a ocorrência do desastre a infraestrutura original frequentemente fica completamente destruída, daí a necessidade de equipamentos robustos que possam ser montados e desmontados facilmente, possibilitando que sejam extremamente adaptáveis e preparados para o inesperado já que as circunstâncias podem mudar rapidamente de um momento para outro.

As operações são, geralmente, limitadas no tempo e na área de atuação e a assistência prestada pelos Fuzileiros Navais visa suplementar ou complementar os esforços dos órgãos ou agências de defesa civil da nação vitimada, os quais têm a responsabilidade primária pelas ações humanitárias em seu país. Estas operações podem ser executadas por efetivos desde uma fração de tropa até uma força-tarefa composta por elementos de várias forças e/ou países que visam prover serviços e itens essenciais às populações vitimadas, conforme descrito na figura 2. 
Figura 2 - Operações Humanitárias

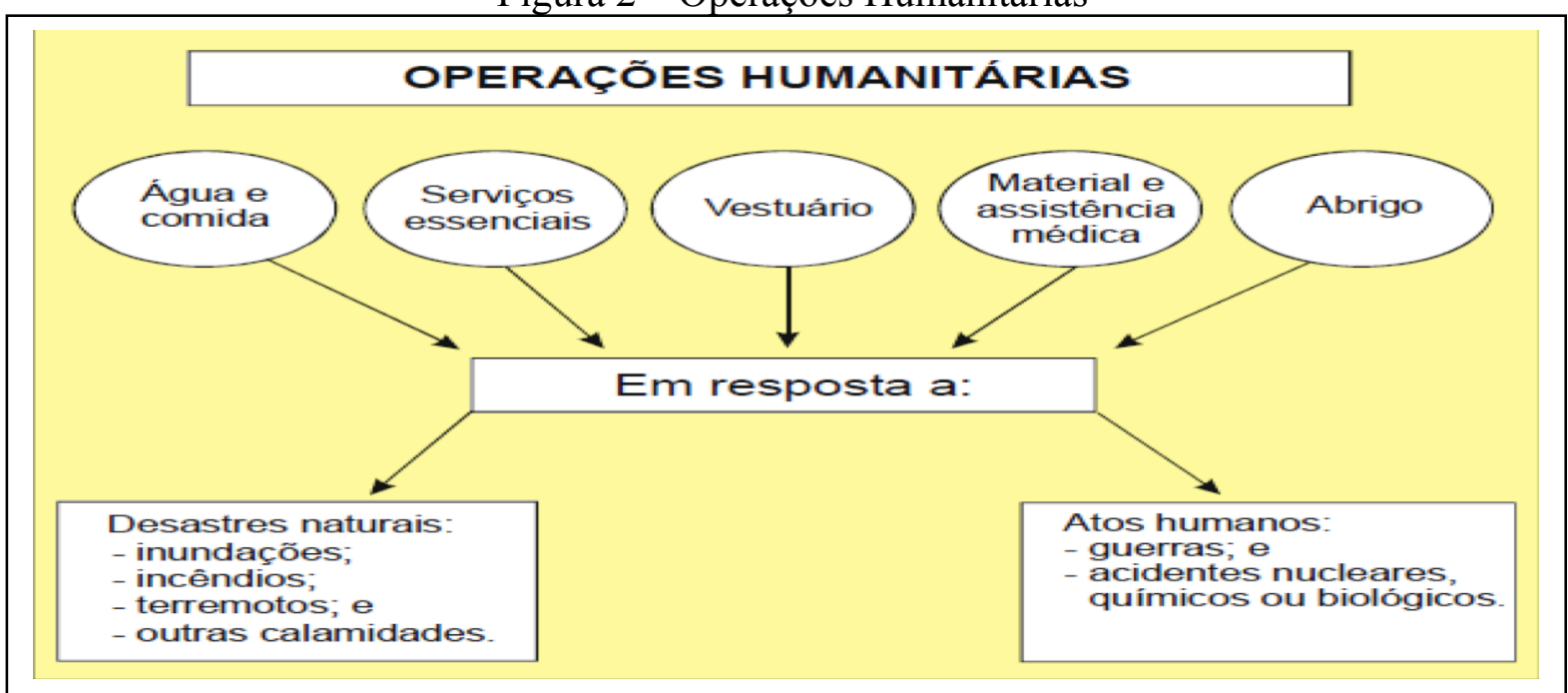

Fonte: (CGCFN 1-13, 2008)

A habilidade do comandante do GptOpFuzNav em trabalhar com outras organizações de distintas origens e variadas metodologias é essencial para o cumprimento da missão em uma Operação Humanitária. Um bom relacionamento entre as forças militares, as autoridades locais, agências nacionais e internacionais envolvidas e a própria população civil facilitarão a realização das tarefas. O local de coordenação das atividades, reunião de recursos e concentração dos meios necessários é o Centro de Operações Civis-Militares (COCM).

As representações locais proveem ao comandante do Grupamento Operativo o trânsito necessário nas esferas civil e política, tanto para ter as suas necessidades atendidas como para apresentar suas considerações operativas, resultando em um apoio consistente às suas ações, com respaldo das autoridades governamentais. Adicionalmente, o COCM é útil às diversas organizações envolvidas porque evita perda de rumo nos trabalhos, concentrando os esforços de todos onde e quando se fizerem necessários.

Embora as forcas militares possam apresentar uma defasagem em relação às organizações de ajuda humanitária, tanto na sua chegada à área de emergência quanto em sua experiência neste tipo de operação, elas trazem consigo um grande suporte logístico, o que é sempre bem-vindo e reconhecido como imprescindível por estas organizações. Como observa-se na figura 3. 
Figura 3 - Relacionamentos do COCM

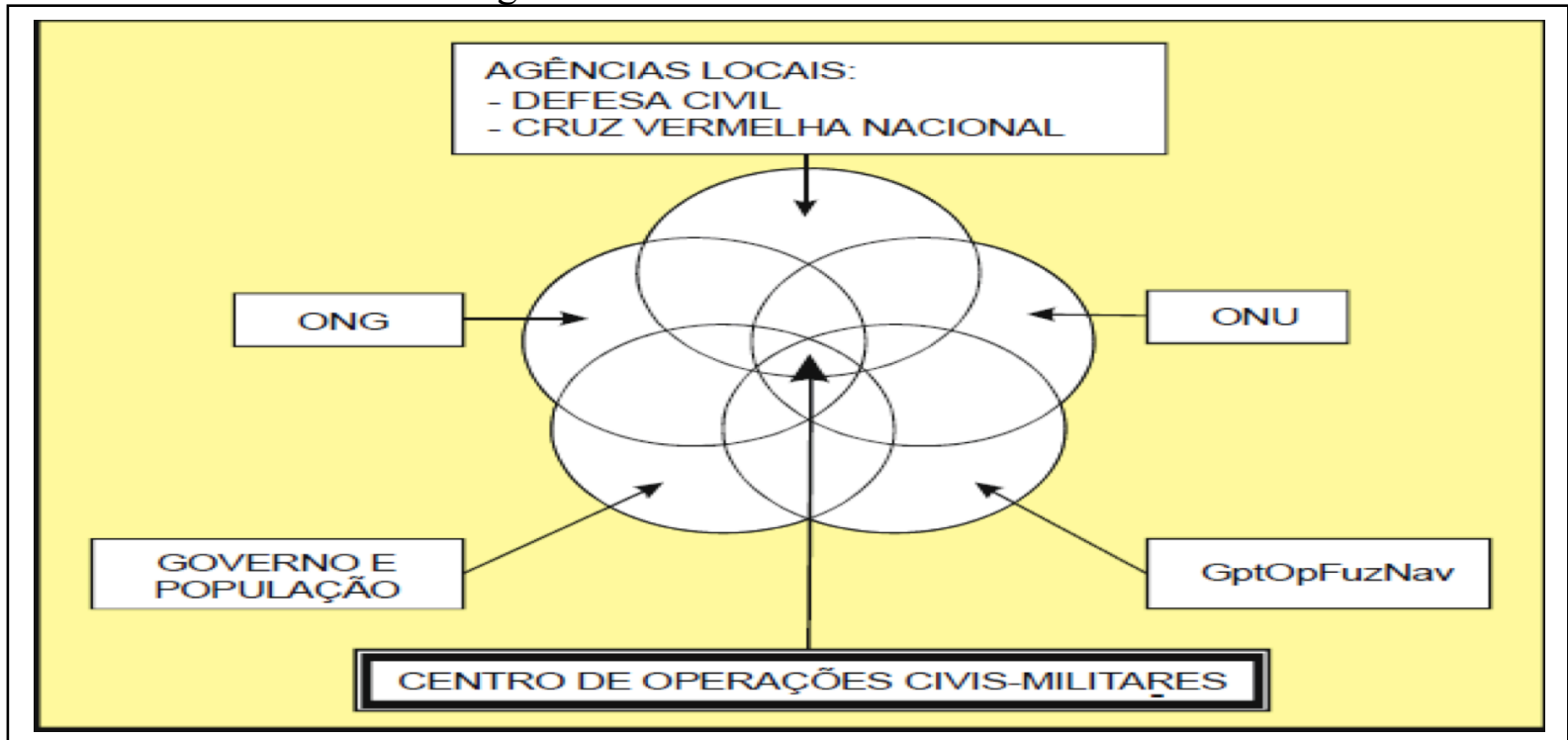

Fonte: (CGCFN 1-13, 2008)

\section{Terremoto no Chile}

Em 27 de fevereiro de 2010, um terremoto de 8,8 graus atingiu o centro-sul do Chile, sendo o maior tremor desde 1960. O terremoto desencadeou um tsunami, que provocou ondas que invadiram até 300 metros de terra firme.

O Governo Brasileiro ofereceu ajuda humanitária ao Governo Chileno, de forma que ficou acordado a instalação de um Hospital de Campanha na cidade de Concepcion. Foi ativada a estrutura de Grupamento Operativo de Fuzileiros Navais, sendo empregado na operação 102 militares, sendo 48 da área de saúde nucleados na Diretoria de Saúde da Marinha e 54 para apoio nucleados no Batalhão Logístico de Fuzileiros Navais. Três dias após a ativação, o Hospital de Campanha já estava realizando atendimentos em território chileno, mostrando o caráter expedicionário por excelência do Corpo de Fuzileiros Navais.

Foram realizados 6 vôos em aeronave C-130 Hercules pela Forca Aérea Brasileira no trajeto Rio de Janeiro - Santiago para transportar pessoal e material. Num primeiro momento, o hospital seria instalado em Concepcion, entretanto momentos antes da decolagem do primeiro vôo decidiu-se pela instalação na região de Cerro Navia, periferia de Santiago. Isto exemplifica como são rápidas as mudanças no planejamento de uma Operação Humanitária e como é importante a organização em forma de componentes o que permite uma maior flexibilidade e rapidez na tomada de decisões.

A decisão da mudança do local inicialmente previsto deveu-se a destruição de quatro grandes hospitais na região de Cerro Navia. O Hospital de Campanha brasileiro atuou substituindo o Hospital Felix Bulnes.

Foi embarcado ração operativa e água para um período de 60 dias, entretanto o tempo de atuação em território chileno foi de 45 dias. Foram realizados mais de 4500 atendimentos médicos, visto que o hospital tinha capacidade de realizar cirurgias de médio porte, exames de laboratório, Raio X convencional e ultrassonografia.

Cabe ressaltar, durante o período da missão, a prontificação de um plano de evacuação em que foram realizados exercícios para fixar a rota de fuga em caso da ocorrência de novo tremor. 


\section{Desabamentos em Nova Friburgo}

Em 2011, no inicio do mês de janeiro a região serrana do Rio de Janeiro foi acometida por fortes chuvas que causaram inúmeros desabamentos, ocasionando centenas de mortes e desaparecimentos.

Por determinação do Comando da Força de Fuzileiros da Esquadra, após expedição de diretiva do Comando de Operações Navais, foi ativado o Grupamento Operativo de Fuzileiros Navais- Nova Friburgo, que após 12 horas do seu acionamento já estava na cidade de Nova Friburgo com o intuito de apoiar as ações da Defesa Civil do estado do Rio de Janeiro e mobiliar um Hospital de Campanha.

Foram empregados 180 militares sendo 50 da área de saúde e 130 de apoio, além de 42 viaturas dentre elas ambulâncias UTI, carretas tipo cavalo mecânico e aquelas que foram de grande valia para as operações de apoio: o caminhão 5TON 4x4 UNIMOG. A grande vantagem desta viatura para os demais caminhões era a altura do seu diferencial com relação ao chão, que permitia adentrar terrenos cobertos de lama sem atolar. Alem disso, foram empregados dois helicópteros, um Super Puma e um Esquilo.

O cenário da cidade era desolador, tanto que a primeira tarefa do GptOpFuzNav Nova Friburgo, em paralelo com a montagem do Hospital de Campanha na sede da prefeitura de Nova Friburgo, foi o transporte de corpos do ginásio municipal (local onde foram concentrados os corpos pelo IML) para o cemitério.

Foi montado um Centro de Operações coordenado pela Defesa Civil de forma que este local era o centro nervoso da operação, já que nele eram tomadas todas as decisões de como empregar as viaturas e efetivos nas ações de busca e resgate, além de concentrar as solicitações da população.

A comoção foi nacional e com isso o número de doações e voluntários chegou a ser maior do que o necessário e isso acabou gerando problemas, exemplo disso era que muitos voluntários levavam doações diretamente para Nova Friburgo, entretanto não existiam locais suficientes para o armazenamento de tantas doações. Com isso durante a operação em trabalho conjunto com a imprensa foi divulgado para que as doações se concentrassem nos quartéis do Rio de Janeiro e conforme iam abrindo espaços de armazenagem nos galpões esses materiais eram transportados e distribuídos nas áreas de reuniões de desabrigados.

O Hospital de Campanha funcionou durante 14 dias realizando 2205 atendimentos dentre eles de clínica cirúrgica, ortopedia, pediatria e odontologia. Nas ações de apoio à defesa civil foram realizados transportes de equipes médicas, resgate de pessoal, pequenos trabalhos de engenharia e outras atividades solicitadas que demandassem viaturas pesadas, leves e helicópteros. Com o emprego dos meios de Fuzileiros Navais e aeronavais foi possível apoiar as ações realizadas em locais distantes e em condições adversas em todo o município.

\section{Conclusão}

As Operações Humanitárias requerem um planejamento especial, diferente do planejamento usual do Corpo de Fuzileiros Navais no cumprimento de sua principal tarefa que é projetar poder sobre terra através de uma Operação Anfíbia. Faz-se necessário uma íntima cooperação com diversos atores do cenário nacional e internacional, como a Organização das Nações Unidas, o Movimento da Cruz Vermelha Internacional e diversas organizações não-governamentais. Essa cooperação evidencia a importância do conhecimento do modus operandi do Corpo de Fuzileiros Navais por parte destas organizações civis, pois durante a realização das Operações Humanitárias todos partilham do mesmo propósito que é o de salvar vidas, diminuir o sofrimento do povo e contribuir para a reconstrução da região afetada, aceitando um grande risco para suas próprias vidas. 
A realização de exercícios conjuntos entre as instituições civis e militares durante "tempos de paz" podem ser um caminho para que no futuro o sofrimento de habitantes das regiões que sofram algum tipo de desastre possa ser amenizado e mais vidas possam ser preservadas.

\section{Referências}

BRASIL. Ministério da Defesa. Estratégia Nacional de Defesa. Brasília, DF, 2008

BRASIL. Marinha do Brasil. Estado Maior da Armada. EMA-305: Doutrina Básica da Marinha. Brasília, DF, 2004

BRASIL. Marinha do Brasil. Corpo de Fuzileiros Navais. CGCFN-1-13: Manual de Operações Humanitárias dos Grupamentos Operativos de Fuzileiros Navais, Rio de Janeiro, 2008.

BRASIL. Marinha do Brasil. Corpo de Fuzileiros Navais. CGCFN-0-1: Manual Básico de Grupamentos Operativos de Fuzileiros Navais, Rio de Janeiro, 2013.

VAN WASSENHOVE, LN. (2006) - Humanitarian aid logistics: supply chain management in high gear. Journal of the Operational Research Society. n.57, p.476. 